\title{
Direct enhancement of readiness for wartime critical specialties by civilian-military partnerships for neurosurgical care: residency training and beyond
}

\author{
David H. Shin, MD, ${ }^{1}$ Kristopher G. Hooten, MD, ${ }^{2}$ Brian D. Sindelar, MD, ${ }^{1}$ Brian M. Corliss, MD, ${ }^{1}$ \\ William R. Y. Carlton Jr., MD, ${ }^{1}$ Christopher P. Carroll, MD, ${ }^{1}$ Jeffrey M. Tomlin, MD, ${ }^{3}$ and \\ W. Christopher Fox, MD'1
}

${ }^{1}$ Department of Neurological Surgery, University of Florida, Gainesville, Florida; ${ }^{2}$ Division of Neurosurgery, Department of Surgery, Tripler Army Medical Center, Honolulu, Hawaii; and ${ }^{3}$ Department of Neurological Surgery, Naval Medical Center, San Diego, California

\begin{abstract}
Military neurosurgery has played an integral role in the development and innovation of neurosurgery and neurocritical care in treating battlefield injuries. It is of paramount importance to continue to train and prepare the next generation of military neurosurgeons. For the Army, this is currently primarily achieved through the military neurosurgery residency at the National Capital Consortium and through full-time out-service positions at the Veterans Affairs-Department of Defense partnerships with the University of Florida, the University of Texas-San Antonio, and Baylor University. The authors describe the application process for military neurosurgery residency and highlight the training imparted to residents in a busy academic and level I trauma center at the University of Florida, with a focus on how case variety and volume at this particular civilian-partnered institution produces neurosurgeons who are prepared for the complexities of the battlefield. Further emphasis is also placed on collaboration for research as well as continuing education to maintain the skills of nondeployed neurosurgeons. With ongoing uncertainty regarding future conflict, it is critical to preserve and expand these civilian-military partnerships to maintain a standard level of readiness in order to face the unknown with the confidence befitting a military neurosurgeon.
\end{abstract}

https://thejns.org/doi/abs/10.3171/2018.8.FOCUS18387

KEYWORDS military neurosurgery; traumatic brain injury; VA-DoD; Veterans Affairs-Department of Defense; residency education; collaboration; continuing education

$\mathrm{M}$ ILITARY neurosurgery has played an integral part in the development and innovation of neurosurgery and neurocritical care in treating battlefield injuries. ${ }^{4}$ The efficiency and expertise of military neurosurgery reaches a pinnacle during episodes of conflict, as demonstrated by more than 7500 neurosurgical procedures being performed during US conflicts from 2002 to $2016 .{ }^{26}$ Today these numbers have exponentially decreased, but during these times of peace and relatively low conflict, maintaining the types of neurosurgical proficiency required in battlefield environments (Fig. 1) is challenging for active-duty neurosurgeons. It is during times such as the present that civilian-military practice integration provides a benefit to both groups in the US. ${ }^{5}$
Recent public scrutiny regarding the qualifications of military subspecialty surgeon $\mathrm{s}^{23}$ has led to increasing interest in the partnering of military treatment facilities (MTFs) with civilian institutions in order to increase surgical case volume, thereby maintaining readiness. These partnerships have existed outside of neurosurgery for the past 10-20 years. ${ }^{918,25}$ Within neurosurgery, civilian partnerships have also existed with regard to residency training; residents at the military's sole neurosurgical training program at the National Capital Consortium (NCC) have rotations at several civilian institutions such as the University of Maryland Shock Trauma Center and the Children's National Medical Center. Additionally, there are ongoing Veterans Affairs-Department of Defense (VA-DoD) agreements

ABBREVIATIONS ACGME = Accreditation Council for Graduate Medical Education; FTOS = full-time out-service; $M$ MTF = military treatment facility; NCC = National Capital Consortium; NMCSD = Naval Medical Center San Diego; UCSD = University of California San Diego; UF = University of Florida; VA-DoD = Veterans Affairs-Department of Defense.

SUBMITTED July 31, 2018. ACCEPTED August 28, 2018.

INCLUDE WHEN CITING DOI: 10.3171/2018.8.FOCUS18387. 


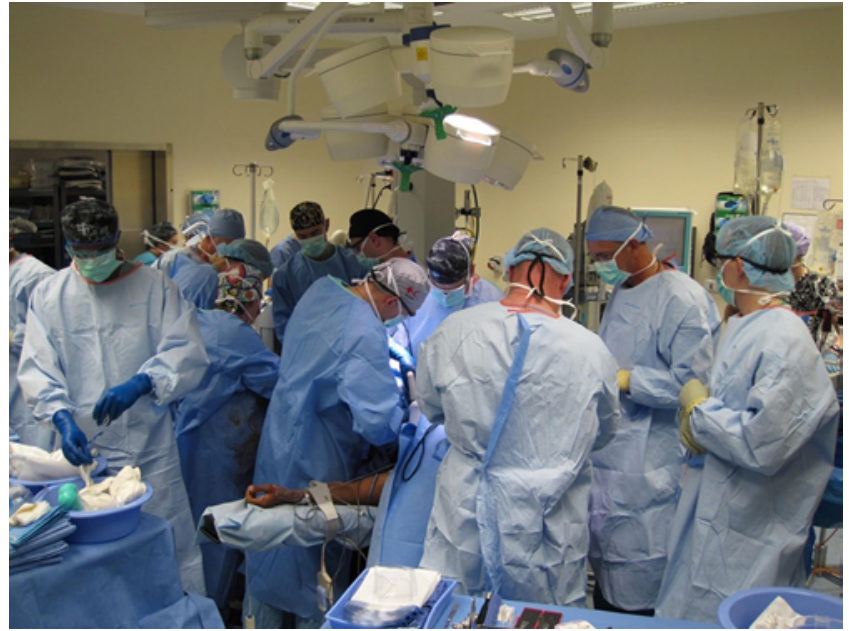

FIG. 1. Deployed neurosurgeon at head of patient operating in an Afghanistan multispecialty surgical team.

for neurosurgery residency training at the University of Florida (UF), the University of Texas-San Antonio, and Baylor University, as well as the former agreement with the University of Washington. Currently, 3 active-duty neurosurgeons have graduated from UF and 1 has graduated from the University of Texas-San Antonio. Eight residents are currently in training between these 4 programs, with 1 resident at the University of Washington and 1 at Baylor. One qualified active-duty military applicant per year is taken by each program through the military match and the full-time out-service (FTOS) program. These relationships were formed to increase the rate of fully trained neurosurgeons to supplement the residency program at the NCC. Importantly, they have played a role in the broader effort to avoid the significant staffing shortages seen previously in active-duty military neurosurgery billets.

The benefits of these partnerships cannot be understated. This is especially true given the exposure of residents to highly productive academic environments that will afford them opportunities to become leaders in organized neurosurgery and also expose them to a wide case variety and volume that will give each graduate the tools and capabilities to face the complexities of battlefield trauma with confidence (Fig. 2). The purpose of this paper is to highlight the importance of civilian-military partnerships with regard to training, specifically describing our experience with the application for and training through the VADoD agreement at UF, as well as its role in postgraduate continuing education to enhance wartime readiness.

\section{Application Process}

The pathways to military neurosurgery have been described previously, with an emphasis on the financial aspects of this decision. ${ }^{15}$ However, the details of the application for military neurosurgical residency are not generally well known given the overall small size of the field combined with the complexities of the military match, which typically have many case-by-case exemptions. In general, although some differences exist between the branches of service, medical students with an interest in military

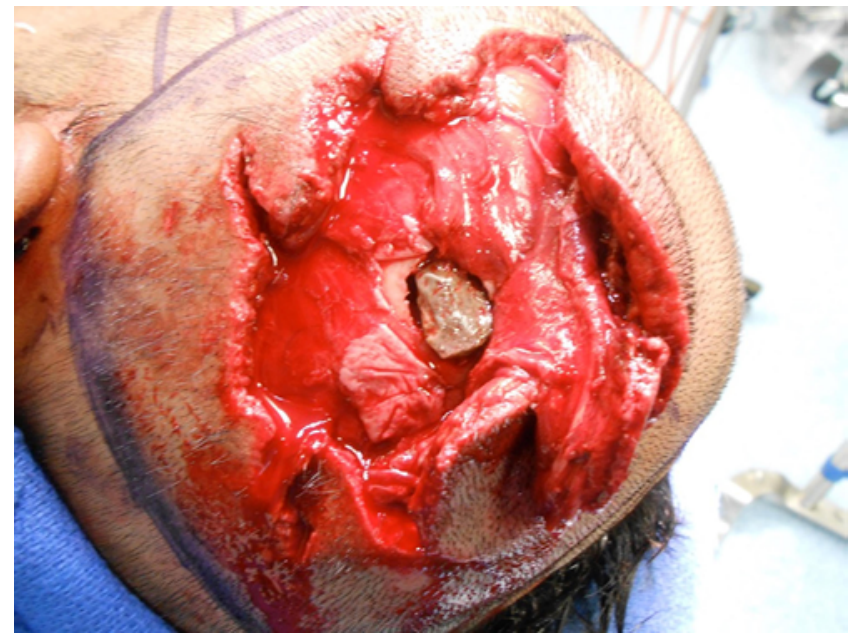

FIG. 2. An example of the complex wounds that may be encountered by deployed neurosurgeons in the battlefield setting. These types of wounds are not frequently encountered during routine practice at MTFs, illustrating the continued need for attending neurosurgeons to be exposed to trauma cases prior to deployment.

neurosurgery should participate in a subinternship at the neurosurgical residency program at the NCC. Once this is complete, Army students may choose to rotate at one of the established VA-DoD locations. To date, for reasons that are not entirely clear, the majority of VA-DoD residency positions have been filled by Army residents (with a single exception from the Air Force), although there are no regulations preventing Navy or Air Force medical officers from participating. In the current environment, the pathway to neurosurgery residency other than the NCC program is less clear for non-Army medical students. Most choose to perform subinternships at nonmilitary programs and subsequently enter the civilian match, hoping that their request for neurosurgical training, either through FTOS or via other programs such as Naval Active Duty Delay for Subspecialists (NADDS), will be approved. The number of spots allocated per service branch is then determined by need on a year-to-year basis by the Joint Service Graduate Medical Education Selection Board. Total spots include both the Active/FTOS (NCC and VA-DoD) spots and any civilian deferments. Students not selected for the military match but selected to train in neurosurgery will then participate in the civilian match, where they are placed on inactive reserve status. Residents in FTOS are on active duty, receiving full pay and benefits typically at the grade of O-3 as their counterparts do at the NCC.

\section{Training at the VA-DoD Program Trauma Cases}

Residents in the FTOS are trained in an equivalent manner with their civilian coresidents at the program. Neurosurgical training at UF primarily exists at the UF Health Shands Hospital, which is a level I trauma center housing more than 1200 total beds. Data from our institution over the last 5 years comparing the case logs of the 3 recently graduated military residents to all other civilian residents indicate that the military residents were all within 
TABLE 1. Case log data of all graduates from the UF neurosurgery residency between 2014 and 2018

\begin{tabular}{|c|c|c|c|c|c|c|c|c|c|c|}
\hline Resident & $\begin{array}{c}\text { Cranial Trauma } \\
(40)\end{array}$ & $\begin{array}{c}\text { Cranial Tumor } \\
(60)\end{array}$ & $\begin{array}{c}\text { Cranial Vascular } \\
\text { (NA) }\end{array}$ & $\begin{array}{c}\text { CSF Diversion } \\
\text { (10) }\end{array}$ & $\begin{array}{c}\text { ACDF } \\
(25)\end{array}$ & $\begin{array}{l}\text { PCF } \\
\text { (15) }\end{array}$ & $\begin{array}{c}\text { Lumbar Disc } \\
\text { (25) }\end{array}$ & $\begin{array}{l}\text { TLF } \\
(20)\end{array}$ & $\begin{array}{l}\text { EVD } \\
(10)\end{array}$ & $\begin{array}{l}\text { ICP Monitor } \\
(5)\end{array}$ \\
\hline 1 & 105 & 163 & 48 & 95 & 65 & 46 & 135 & 185 & 62 & 7 \\
\hline $2^{*}$ & 74 & 109 & 41 & 91 & 52 & 51 & 146 & 113 & 65 & 10 \\
\hline 3 & 101 & 128 & 46 & 117 & 58 & 70 & 119 & 147 & 79 & 21 \\
\hline 4 & 73 & 117 & 41 & 100 & 61 & 73 & 137 & 104 & 52 & 23 \\
\hline 5 & 92 & 139 & 40 & 78 & 48 & 73 & 127 & 105 & 52 & 15 \\
\hline 6 & 116 & 158 & 52 & 100 & 65 & 73 & 115 & 109 & 51 & 54 \\
\hline 7 & 90 & 123 & 46 & 103 & 51 & 54 & 117 & 124 & 41 & 34 \\
\hline $8^{*}$ & 89 & 129 & 54 & 97 & 76 & 75 & 152 & 180 & 70 & 12 \\
\hline $9^{*}$ & 105 & 118 & 54 & 112 & 33 & 50 & 93 & 132 & 81 & 70 \\
\hline 10 & 124 & 105 & 70 & 94 & 43 & 37 & 90 & 102 & 95 & 13 \\
\hline 11 & 103 & 103 & 48 & 94 & 42 & 45 & 105 & 126 & 97 & 12 \\
\hline 12 & 95 & 92 & 26 & 81 & 68 & 86 & 135 & 106 & 36 & 9 \\
\hline 13 & 53 & 88 & 39 & 69 & 39 & 22 & 84 & 76 & 8 & 1 \\
\hline Mean & 94 & 121 & 47 & 95 & 54 & 58 & 120 & 124 & 61 & 22 \\
\hline SD & 19 & 23 & 10 & 13 & 13 & 18 & 22 & 31 & 25 & 20 \\
\hline
\end{tabular}

$\mathrm{ACDF}=$ anterior cervical discectomy and fusion; $\mathrm{EVD}=$ external ventricular drain; $\mathrm{ICP}=$ intracranial pressure; $\mathrm{NA}=$ not applicable; $\mathrm{PCF}=$ posterior cervical fusion; $\mathrm{TLF}$ $=$ thoracolumbar fusion.

Minimum requirements (number of cases) as determined by the ACGME are given in parentheses.

* Military residents.

1.5 SDs of the mean case numbers for cranial and spinal trauma (Table 1). Generally speaking, all graduates recorded nearly double the Accreditation Council for Graduate Medical Education (ACGME) minimum case log requirements ${ }^{1}$ for cranial and cervical trauma. Additionally, there was an average 7-fold increase in thoracolumbar instrumentation and fusion above the ACGME minimum. With current guidelines from the Brain Trauma Foundation recommending intracranial pressure monitoring for patients who have suffered severe traumatic brain injury, ${ }^{6}$ graduates were well versed in the placement of these devices, registering a greater than 5-fold increase over the ACGME minimum for intracranial monitoring. These data indicate that training in conjunction with an appropriate high-volume academic center allows for more than sufficient exposure to traumatic cases, allowing for optimal care in the battlefield setting.

\section{Nontrauma Cases}

More than trauma care is needed to maintain the competency and readiness of all military medical personnel in war and peace. ${ }^{5}$ Additional neurosurgical care is needed to maintain a readily deployable force, care for dependents and retirees, and provide care to the local population while deployed or performing humanitarian missions. Having a broad scope of practice during training is necessary to accomplish this goal, which can be achieved by the civilian partnership afforded by the VA-DoD program at UF. Similar to what was seen regarding trauma cases, graduates from UF registered well above the ACGME standards for cranial oncology, CSF diversion, basic degenerative spine disease, and even open vascular cases. At UF, where 3800 neurosurgical cases, in addition to 700-800 endovascular neurosurgery procedures and 500 radiosurgery procedures are performed annually, future military neurosurgeons are well prepared for the broad scope of cases they will eventually see on active duty. Given the goal of DoD health care to treat active-duty personnel, retirees, and dependents, this type of training exposure is essential.

There are limited data to suggest that approximately 15-30 cases are required to meet a standard level of individual proficiency for a particular procedure, ${ }^{16}$ and the minimum requirements set out by the ACGME are reflective of this. The manner in which the UF VA-DoD program exceeds these minimums highlights the clear benefit of having this civilian partnership, which will result in well-trained neurosurgeons who are fully prepared for the battlefield.

\section{Additional Training Requirements}

Although civilian and military residents are treated in an equivalent manner with regard to surgical caseload at the UF VA-DoD program, there are certainly differences in training with regard to time spent outside of the operating room. All military residents are assigned to the Army Medical Department (AMEDD) Student Detachment (ASD) as a part of the 187th Medical Battalion, which is based out of Fort Sam Houston, Texas. Regular reporting to the battalion commander is required. Residents are also expected to maintain an appearance at all times that befits an officer according to their service (e.g., Army Regulation $670-1^{8}$ ). Additionally, military residents must partake in a biannual, service-specific physical fitness test in order to maintain readiness. Furthermore, these residents undergo regular officer evaluations, which in turn typically allows for promotion from O-3 to O-4 during postgraduate year 6 . 


\section{Research}

Another important aspect of civilian-military collaboration comes in the realm of research. Although the ongoing conflicts in Iraq and Afghanistan have advanced the neurosurgical literature with significant insight into wartime conditions and procedures, $, 3,13,17,22$ there is ample opportunity to directly apply the expertise gained overseas into research paradigms in civilian settings. For example, UF, along with most academic institutions that are associated with highvolume trauma centers, maintains its own trauma database from which ongoing clinical investigations are being generated, and yet an organized link to military applications remains untapped. However, in keeping with the aim of the UF VA-DoD partnership, much academic support has been given to the individual military residents to produce a significant number of relevant research articles with direct and indirect battlefield applications. . $^{27,10-12,19-21}$

There are already similar ongoing collaborative efforts in the field of orthopedics with the Major Extremity Trauma and Rehabilitation Consortium (METRC), which is a combination effort of 22 level I civilian trauma centers and 4 MTFs. Their purpose is to disseminate battlefield knowledge and techniques "in civilian practice, so they are available during future conflicts."'14 However, one of the major limitations of the contributions from MTFs to this database is the significantly higher volume of patients seen at civilian centers, which can be nearly 11 times the comparative volume of an $\mathrm{MTF},{ }^{24}$ highlighting the continuing need for civilian collaboration to advance military medicine and vice versa. A similar model should be applied to the field of neurosurgery, so that the lessons learned through the precious sacrifices of our service members can be carried forward to benefit others in the future.

\section{Preparedness}

To date, a single Army graduate from the UF VA-DoD program has successfully completed an overseas tour. Over a 6-month period, this graduate was deployed to the Baghdad Diplomatic Support Center as a part of its role 3 Combat Support Hospital, which is the highest level of care in the combat theater. During this time, he performed a number of challenging cases for blunt and penetrating cranial trauma for which he was well prepared given his surgical training experience. He was also awarded the Army Commendation Medal and the Joint Service Achievement Medal for his exemplary actions, indicating that the professionalism and leadership characteristics developed during his civilian residency effectively translated into military service.

\section{Continuing Education}

Upon completion of residency training, the small number of graduates educated using this model have been generally well prepared for their active-duty service and deployment. However, the challenge remains to maintain this level of readiness, due to the overall diminishing volume of active-duty military neurosurgical need. Therefore, it is necessary to expand civilian partnerships both at an institutional and on an individual level. Institutional partnerships exist already on a local level at the San Antonio
Military Medical Center (SAMMC) at Fort Sam Houston and William Beaumont Army Medical Center (WBAMC) at Fort Bliss. Both institutions are currently integrated into local civilian trauma networks, which is optimal from a systems readiness standpoint. Military physicians, nurses, and technicians all must be familiar with standard trauma protocol within the context of an institution in order to appropriately translate those skills into a nonstandard battlefield environment.

However, it is also important to maintain individual operative readiness from a technical standpoint for the military neurosurgeon. The Naval Medical Center San Diego (NMCSD) recognized the value of collaboration between academic and military neurosurgery through recent efforts to integrate active-duty neurosurgeons assigned to NMCSD into the trauma service at the University of California San Diego (UCSD). As NMCSD sought to provide cooperative ongoing maintenance of critical skills for treatment of neurosurgical trauma patients seen across the UCSD trauma system, a memorandum of understanding was established between NMCSD and the UCSD health system. This support was directly in accordance with directives from the National Defense Authorization Act (NDAA) of 2017, and aligned military neurosurgeons with their civilian counterparts in the nearest academic medical center. In providing this support, it has been the Navy's goal to optimally integrate staff neurosurgeons into the culture of trauma care by providing a maximum exposure assignment.

NMCSD neurosurgery has thus provided board eligible/ certified neurosurgeons as a pilot program to the UCSD academic center on a rotating basis for the coming years to lead and direct the care of patients with head trauma presenting for care to this civilian health system. The call coverage for the dedicated trauma service is coordinated with the chairperson of the Department of Neurosurgery at UCSD to ensure that maximum experience is gained during these rotations, and Navy neurosurgeons participate in the teaching and supervision of the UCSD neurosurgery residents. Joint UCSD faculty appointments for the Navy personnel will be facilitated to ensure that the ACGME needs and standards are met for the UCSD neurosurgical training program. Given the collective deployment experience of active-duty neurosurgeons overseas, this provides a unique training opportunity and perspective to the neurosurgery residents at UCSD, and exposure to the academic environment and a busy civilian trauma practice benefits the Navy neurosurgeons, with downstream benefits for military patients.

The Navy assignees rotate to UCSD in staggered teams, providing extended assignments through rotating orders at the discretion of the Commanding Officer at NMCSD in accordance with the mutually signed memorandum of understanding. This allows the Navy neurosurgeons to be covered by the Uniformed Services malpractice insurance in performance of their official military duties while assigned to UCSD. This arrangement also allows for the military neurosurgeons to practice under their current unrestricted medical licenses, as required for their military assignment to NMCSD.

Although UCSD will be prevented from billing for the 
specific surgical or professional fees associated with any TRICARE beneficiary cared for by the Navy physicians, UCSD will be able to recover and retain fees associated with the military neurosurgical care of other civilian patients, with the application of these fees into a UCSD fund to support educational opportunities within the institution's neurosurgical department. No professional fees will be paid directly to the Navy or to the individual military neurosurgeons rotating through these assignments.

In order to provide comprehensive neurosurgical care, military neurosurgeons are credentialed for privileges at UCSD commensurate with their level of training and current practice. The chairperson of the Department of Neurosurgery at UCSD coordinates these credentialing efforts to support robust neurosurgical care. However, the primary arrangement is for navy neurosurgeons to provide urgent cranial surgical care, because there is already a robust call system for other urgent noncranial cases. Since the program launch in July 2018, the collaborative service has already exceeded the combined neurosurgical trauma volume seen by the previous 2 Navy deployments through the Kandahar, Afghanistan, deployment cycles. Although this is traditionally a lower-volume station compared to the Army and Air Force involvement in Bagram, this example highlights the extreme discrepancy in trauma cases. Over an extended period of time, this can have significant consequences on an individual neurosurgeon's operative ability. To our knowledge, no other partnership exists within military neurosurgery that allows for an individual neurosurgeon to perform cases at an entirely separate, nonaffiliated, civilian institution.

\section{Conclusions}

In the US armed forces there are a total of 44 slots allocated for fully trained neurosurgeons, of which a relatively high percentage historically have gone unfilled. This speaks to the need for fully prepared neurosurgeons to support the mission of the armed forces at a moment's notice. The VA-DoD partnerships provide crucial support toward this aim by supplementing the high-quality NCC residency through the training of additional battlefield-prepared neurosurgeons. These partnerships also provide access to abundant research opportunities that have the potential to improve outcomes in the management of severe traumatic cranial and spinal injuries, both for the civilian population and our service members. Finally, to maximize preparedness in the postgraduate setting, the logical next step is to continue this type of partnership and collaboration at high-volume, high-acuity trauma centers, which simply do not exist within the current MTF paradigm. As a potential solution to this problem on a national level, we have highlighted institutional examples at the San Antonio Military Medical Center and the William Beaumont Army Medical Center, which should become standard practice at all MTFs. From an individual standpoint, we have described in detail the successful implementation of an exemplary partnership between NMCSD and UCSD. These examples of continuing education should be the rule, rather than the exception. Failure to take full advantage of civilian-military partnerships could place our current and future ser- vice members at risk of receiving neurosurgical care that lacks a foundation of preparation for the challenges faced in wartime injuries. We as a profession owe at least the highest standard to those we serve-soldiers, sailors, marines, and airmen serving the US at home and abroad.

\section{Acknowledgments}

We thank Major Kelvin Wilson, MD, for providing insight into his active-duty and deployment experience.

\section{References}

1. Accreditation Council for Graduate Medical Education: Neurological Surgery Case Log Defined Case Categories and Required Minimum Numbers: Review Committee for Neurological Surgery. Chicago: Accreditation Council for Graduate Medical Education, 2018 (https://www. acgme.org/Portals/0/PFAssets/ProgramResources/160_ Neurological_Surgery_Defined_Case_Categories_and_Required_Minimum_Numbers.pdf) [Äccessed October 15, 2018]

2. Bailes JE, Patel V, Farhat H, Sindelar B, Stone J: Football fatalities: the first-impact syndrome. J Neurosurg Pediatr 19:116-121, 2017

3. Bell RS, Ecker RD, Severson MA III, Wanebo JE, Crandall B, Armonda RA: The evolution of the treatment of traumatic cerebrovascular injury during wartime. Neurosurg Focus 28(5):E5, 2010

4. Bell RS, Mossop CM, Dirks MS, Stephens FL, Mulligan L, Ecker R, et al: Early decompressive craniectomy for severe penetrating and closed head injury during wartime. Neurosurg Focus 28(5):E1, 2010

5. Brandt MM: Civilian-military partnerships. J Trauma Acute Care Surg 82:977-978, 2017

6. Carney N, Totten AM, O'Reilly C, Ullman JS, Hawryluk GWJ, Bell MJ, et al. Guidelines for the Management of Severe Traumatic Brain Injury, ed 4. Campbell, CA: Brain Trauma Foundation, 2016

7. Corliss BM, Hooten KG, Gul SS, Neal D, Murad GJ, Rahman M: Establishing standard performance measures in adult traumatic brain injury patients. Neurosurgery 77:44-50, 2015

8. Department of the Army Headquarters: Wear and Appearance of Army Uniforms and Insignia. Washington, DC: Department of the Army Headquarters, 2014 (https://www. army.mil/e2/c/downloads/337951.pdf) [Accessed October 15, 2018]

9. Grimm J, Johnson K: Saint Louis Center for Sustainment of Trauma and Readiness Skills: a collaborative Air Forcecivilian trauma skills training program. J Emerg Nurs 42:104-107, 2016

10. Hooten KG, Lister JR, Lombard G, Lizdas DE, Lampotang $\mathrm{S}$, Rajon DA, et al. Mixed reality ventriculostomy simulation: experience in neurosurgical residency. Neurosurgery 10:576-581, 2014

11. Hooten KG, Murad GJ: Helmet use and cervical spine injury: a review of motorcycle, moped, and bicycle accidents at a level 1 trauma center. J Neurotrauma 31:1329-1333, 2014

12. Hooten KG, Murad GJ: Helmeted vs nonhelmeted: a retrospective review of outcomes from 2-wheeled vehicle accidents at a level 1 trauma center. Clin Neurosurg 59:126130,2012

13. Klimo P Jr, Ragel BT, Rosner M, Gluf W, McCafferty R: Can surgery improve neurological function in penetrating spinal injury? A review of the military and civilian literature and treatment recommendations for military neurosurgeons. Neurosurg Focus 28(5):E4, 2010 
14. Major Extremity Trauma Research Consortium (METRC): Building a clinical research network in trauma orthopaedics: the Major Extremity Trauma Research Consortium (METRC). J Orthop Trauma 30:353-361, 2016

15. Menger RP, Wolf ME, Lang RW III, Smith DR, Nanda A, Letarte P, et al: Military neurosurgery: a range of service options. Neurosurgery 78:765-774, 2016

16. Neal CJ, Rosner MK: Resident learning curve for minimalaccess transforaminal lumbar interbody fusion in a military training program. Neurosurg Focus 28(5):E21, 2010

17. Ragel BT, Klimo P Jr, Martin JE, Teff RJ, Bakken HE, Armonda RA: Wartime decompressive craniectomy: technique and lessons learned. Neurosurg Focus 28(5):E2, 2010

18. Schulman CI, Graygo J, Wilson K, Robinson DB, Garcia G, Augenstein J: Training forward surgical teams: do militarycivilian collaborations work? US Army Med Dep J 2010 Oct-Dec:17-21, 2010

19. Sindelar B, Bailes J, Sherman S, Finan J, Stone J, Lee J, et al: Effect of internal jugular vein compression on intracranial hemorrhage in a porcine controlled cortical impact model. J Neurotrauma 34:1703-1709, 2017

20. Sindelar B, Shinners M, Sherman S, Erickson K, Patel V, Kubilis P, et al: Reduction in temporary and permanent audiological injury through internal jugular vein compression in a rodent blast injury model. Otol Neurotol 38:1205-1212, 2017

21. Sindelar B, Shinners M, Sherman S, Novak K, Erickson K, Patel V, et al: Internal jugular vein compression: a novel approach to mitigate blast induced hearing injury. Otol Neurotol 38:591-598, 2017

22. Stephens FL, Mossop CM, Bell RS, Tigno T Jr, Rosner MK, Kumar A, et al: Cranioplasty complications following wartime decompressive craniectomy. Neurosurg Focus 28(5):E3, 2010

23. Sternberg S, Huth L: Safety in numbers: low volumes at military hospitals imperil patients. US News \& World Report. April 19, 2018 (https://www.usnews.com/news/nationalnews/articles/2018-04-19/patient-shortage-erodes-militarysurgeons-skills-preparedness-for-war) [Accessed October 15, 2018]
24. Stinner DJ, Wenke JC, Ficke JR, Gordon W, Toledano J, Carlini AR, et al: Military and civilian collaboration: the power of numbers. Mil Med 182 (Suppl 1):10-17, 2017

25. Thorson CM, Dubose JJ, Rhee P, Knuth TE, Dorlac WC, Bailey JA, et al: Military trauma training at civilian centers: a decade of advancements. J Trauma Acute Care Surg 73 (6 Suppl 5):S483-S489, 2012

26. Turner CA, Stockinger ZT, Bell RS, Gurney JM: Neurosurgical workload during US combat operations: 2002 to 2016. J Trauma Acute Care Surg 85:140-147, 2018

\section{Disclaimer}

The views expressed in this article are those of the authors and do not necessarily reflect the official policy or position of the Department of the Army, Department of the Navy, Department of Defense, or the United States Government. Note: All authors are current or former active-duty service members.

\section{Disclosures}

The authors report no conflict of interest concerning the materials or methods used in this study or the findings specified in this paper.

\section{Author Contributions}

Conception and design: Shin, Hooten, Fox. Acquisition of data: Shin. Analysis and interpretation of data: Shin, Fox. Drafting the article: Shin, Hooten, Fox. Critically revising the article: all authors. Reviewed submitted version of manuscript: all authors. Approved the final version of the manuscript on behalf of all authors: Shin.

\section{Correspondence}

David HeeGwang Shin: University of Florida, Gainesville, FL. david.shin@neurosurgery.ufl.edu. 